\title{
Modeling and Optimization of Vehicle Suspension Employing a Nonlinear Fluid Inerter
}

\author{
Yujie Shen, ${ }^{1}$ Long Chen, ${ }^{2}$ Yanling Liu, ${ }^{2}$ and Xiaoliang Zhang ${ }^{2}$ \\ ${ }^{1}$ School of Automotive and Traffic Engineering, Jiangsu University, Zhenjiang 212013, China \\ ${ }^{2}$ Automotive Engineering Research Institute, Jiangsu University, Zhenjiang 212013, China \\ Correspondence should be addressed to Long Chen; chenlong@ujs.edu.cn
}

Received 10 March 2016; Revised 30 May 2016; Accepted 27 June 2016

Academic Editor: Mickaël Lallart

Copyright (c) 2016 Yujie Shen et al. This is an open access article distributed under the Creative Commons Attribution License, which permits unrestricted use, distribution, and reproduction in any medium, provided the original work is properly cited.

\begin{abstract}
An ideal inerter has been applied to various vibration engineering fields because of its superior vibration isolation performance. This paper proposes a new type of fluid inerter and analyzes the nonlinearities including friction and nonlinear damping force caused by the viscosity of fluid. The nonlinear model of fluid inerter is demonstrated by the experiments analysis. Furthermore, the full-car dynamic model involving the nonlinear fluid inerter is established. It has been detected that the performance of the vehicle suspension may be influenced by the nonlinearities of inerter. So, parameters of the suspension system including the spring stiffness and the damping coefficient are optimized by means of QGA (quantum genetic algorithm), which combines the genetic algorithm and quantum computing. Results indicate that, compared with the original nonlinear suspension system, the RMS (rootmean-square) of vertical body acceleration of optimized suspension has decreased by $9.0 \%$, the RMS of pitch angular acceleration has decreased by $19.9 \%$, and the RMS of roll angular acceleration has decreased by $9.6 \%$.
\end{abstract}

\section{Introduction}

Ride comfort is one of the most important performances of the vehicle and is greatly influenced by the vehicle suspension system set between the vehicle body and the wheels. There are mainly three kinds of suspension systems, including active suspension [1-3], semiactive suspension [4-6], and passive suspension. For active suspension and semiactive suspension, they always have a changeable suspension parameter like spring stiffness or damping coefficient to preserve the two desired aims which are vehicle handling and ride comfort. But for passive suspension system, it only has two parallel spring and damper elements. In this case, the vibration isolation performance can be improved by parameters' optimization $[7,8]$ or involving new mechanical element.

In $[9,10]$, inerter was proposed with the property that the force in the mechanical device is proportional to the relative accelerations of the two terminals. It was widely known as "J-damper" [11] in Formula One Racing since it delivered significant performance gains in handling and grip. As a new mechanical network element corresponding to the capacitor, inerter was widely used in passive network synthesis [1214]. Also, the vibration isolation performance of conventional spring-damper isolation system can be significantly improved by involving the inerter, which has been verified in vehicle suspension [15-18], train suspension [19, 20], building suspension [21], dynamic vibration absorber [22-24], and vibration isolation $[25,26]$.

Researches above are all concentrated on the ideal inerter, ignoring considering its nonlinearities. In [27], the nonlinearities including friction, elastic effect, and backlash of a rackand-pinion and ball-screw inerter were taken into consideration. The above study found that the performance of vehicle suspension may be significantly degraded by the nonlinear effects. It seems important to investigate the influences of the nonlinearities of inerter on vehicle suspension system. In $[28,29]$, a new kind of inerter called fluid inerter was proposed and the inner force was investigated, but the effect of the nonlinear model on the suspension performance was not discussed. This paper explores a new vehicle suspension employing the nonlinear fluid inerter. The parameters of the suspension are optimized by using optimal algorithm to 


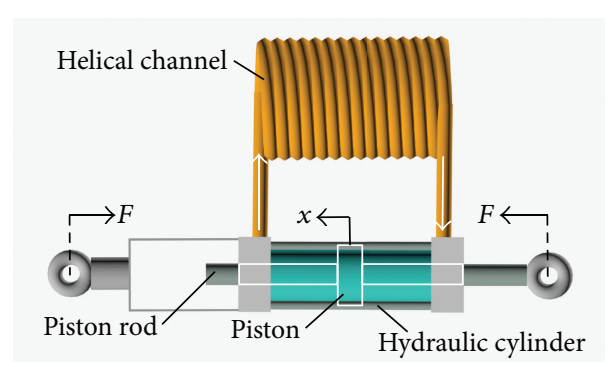

FIGURE 1: Prototype of fluid inerter.

reduce the effect of the nonlinearities, based on the full-car model including the nonlinear inerter. The paper is arranged as follows.

In Section 2, a new fluid inerter is designed and the nonlinearities involving friction and damping force are taken into consideration. Experiments are finished to demonstrate the nonlinear model. Suspension system involving the nonlinear fluid inerter is built in Section 3 and the parameters of the suspension are obtained by means of QGA (quantum genetic algorithm) in Section 4. Dynamic performance of the vehicle suspension is analyzed in Section 5. Finally, some conclusions are shown in Section 6.

\section{Design and Test of Fluid Inerter}

There are many mechanical types of inerter, such as ballscrew inerter, rack-and-pinion inerter [30], hydraulic-motor inerter [31], and fluid inerter [28, 29]. Motion transferred mechanics are used in the device to enlarge the inertia force which is the most meaningful thing to inerter. The dynamic equation of inerter is

$$
F=b\left(\dot{v}_{1}-\dot{v}_{2}\right)
$$

where $F$ is the force in the device, $v_{1}$ and $v_{2}$ are the velocities, and $b$ is the inertance with the unit $\mathrm{kg}$. In this section, a new type of fluid inerter is designed to investigate the nonlinearities.

2.1. Ideal Fluid Inerter. The fluid inerter is similar to rackand-pinion inerter or ball-screw inerter because the fluid flowing in the helical channel can be taken as a "fluid flywheel" to provide the inertia force. The prototype of the fluid inerter with the helical channel outside the cylinder is shown in Figure 1.

In Figure 1, $F$ is the force applied in the fluid inerter and $x$ is the displacement of the piston. The hydraulic cylinder and the piston rod are the two terminals of the fluid inerter. When the piston pushes the fluid in the left of the hydraulic cylinder into the helical channel, the fluid flows through the helical channel into the right hydraulic cylinder in order to compensate the pressure loss.
Firstly, the fluid in the cylinder and the helical channel is taken as nondisclosure and noncompressed. According to [29], the inertance $b$ can be gained as

$$
b=\frac{m}{1+\left(h / 2 \pi r_{4}\right)^{2}}\left(\frac{S_{1}}{S_{2}}\right)^{2},
$$

where $m$ is the mass of the fluid in the helical channel, $S_{1}$ is the effective area of the hydraulic cylinder, $S_{2}$ is the section area of the helical channel, $h$ is the pitch of the helical channel, and $r_{4}$ is the helix radius of the helical channel.

$S_{1}$ can be gained by the equation

$$
S_{1}=\pi\left(r_{2}^{2}-r_{1}^{2}\right),
$$

where $r_{1}$ is the radius of the piston rod and $r_{2}$ is the inside radius of the hydraulic cylinder.

$S_{2}$ can be gained by the equation

$$
S_{2}=\pi r_{3}^{2}
$$

where $r_{3}$ is the radius of the helical channel.

$m$ can be gained by the equation

$$
m=\rho S_{2} l
$$

where $\rho$ is the oil density and $l$ is the length of helical channel and can be approximated as

$$
l=n \sqrt{h^{2}+\left(2 \pi r_{4}\right)^{2}}+2 l_{0}
$$

where $n$ is the circle number of the helical channel and $l_{0}$ is the length from the inlet and outlet to the helical channel.

2.2. Nonlinearities Analysis of Fluid Inerter. When the force $F$ is applied to the fluid inerter, both the friction caused by the motion of piston rod and hydraulic cylinder $f$ and the damping force caused by the viscosity of the fluid $f_{c}$ will block the motion of the piston. The dynamic equation is

$$
F-f-f_{c}=b \ddot{x} .
$$

The friction model can be described by the Column Friction Model as follows:

$$
f=f_{0} \operatorname{sign}(v),
$$

where $f_{0}$ is the amplitude of the friction, $v$ is the velocity of the piston, and $\operatorname{sign}(v)$ is a symbolic function; it is 1 when $v>0$ and -1 when $v<0$. The direction of friction $f$ between the piston and hydraulic cylinder is related to the velocity of the piston and has the constant value.

For a hydraulic device, the damping force caused by the viscosity of the fluid is the most important impact on the dynamic performance. According to the Hagen Poiseuille Law, the flow of the fluid in the helical channel $Q$ and the pressure drop between the two terminals $\Delta p$ have the relation as follows:

$$
Q=\frac{\pi r_{3}^{4}}{8 \mu l} \Delta p
$$

in which $\mu$ is viscosity. 


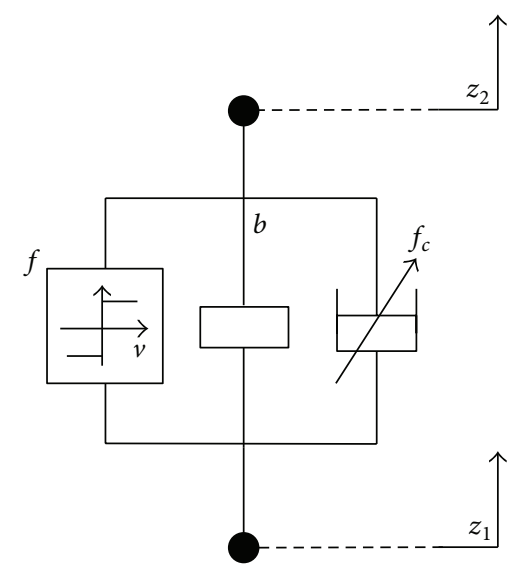

Figure 2: Dynamic model of fluid inerter.

The average flow velocity of fluid in the helical channel $u$ is

$$
u=\frac{Q}{S_{2}}=\frac{r_{3}^{2}}{8 \mu l} \Delta p
$$

A fluid flow entering a new channel will also experience an energy loss at the inlet and outlet of the hydraulic cylinder; the empirical formula for the resulting pressure drop is given in [32]. The pressure drop across the inlet and outlet is thus estimated to be

$$
\begin{aligned}
& \Delta p_{1}=0.5 \frac{\rho u^{2}}{2}, \\
& \Delta p_{2}=\frac{\rho u^{2}}{2} .
\end{aligned}
$$

According to the volume conservation law,

$$
S_{1} \dot{x}=S_{2} u
$$

So, the damping force of the inerter can be gained as follows:

$$
f_{c}=\left(\Delta p+\Delta p_{1}+\Delta p_{2}\right) S_{1}=\frac{3 \rho S_{1}^{3}}{4 S_{2}^{2}} \dot{x}^{2}+\frac{8 \mu l S_{1}^{2}}{r_{3}^{2} S_{2}} \dot{x}
$$

The damping force is related not only to the velocity but also to the square of the velocity of the piston. The coefficient of the square of the velocity is set as $C_{1}$ and the coefficient of the velocity is set as $C_{2}$.

The dynamic model of the fluid inerter can be shown in Figure 2.

In Figure $2, z_{1}$ and $z_{2}$ are displacements.

The total force of the inerter can be gained as follows:

$$
\begin{aligned}
F= & f_{0} \operatorname{sign}\left(\dot{z}_{1}-\dot{z}_{2}\right)+C_{1}\left(\dot{z}_{1}-\dot{z}_{2}\right)^{2}+C_{2}\left(\dot{z}_{1}-\dot{z}_{2}\right) \\
& +b\left(\ddot{z}_{1}-\ddot{z}_{2}\right) .
\end{aligned}
$$

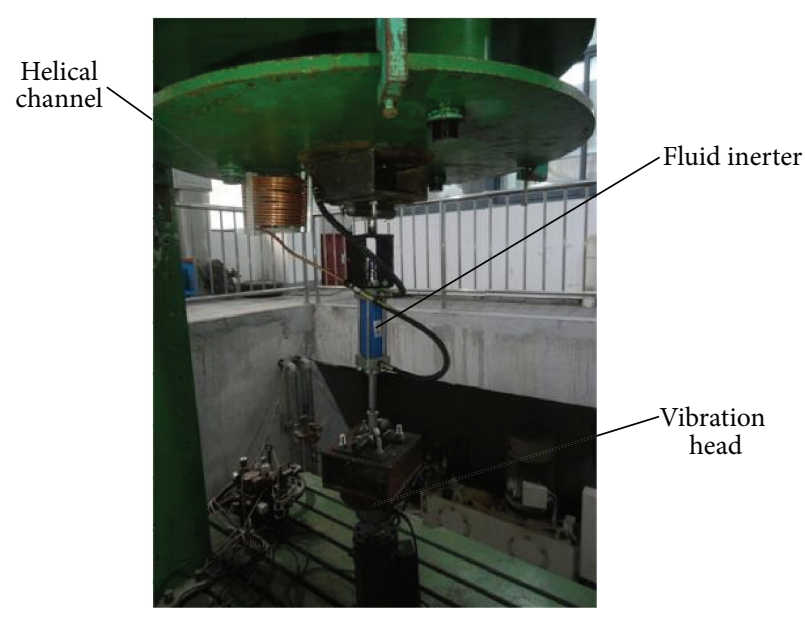

Figure 3: Bench test.

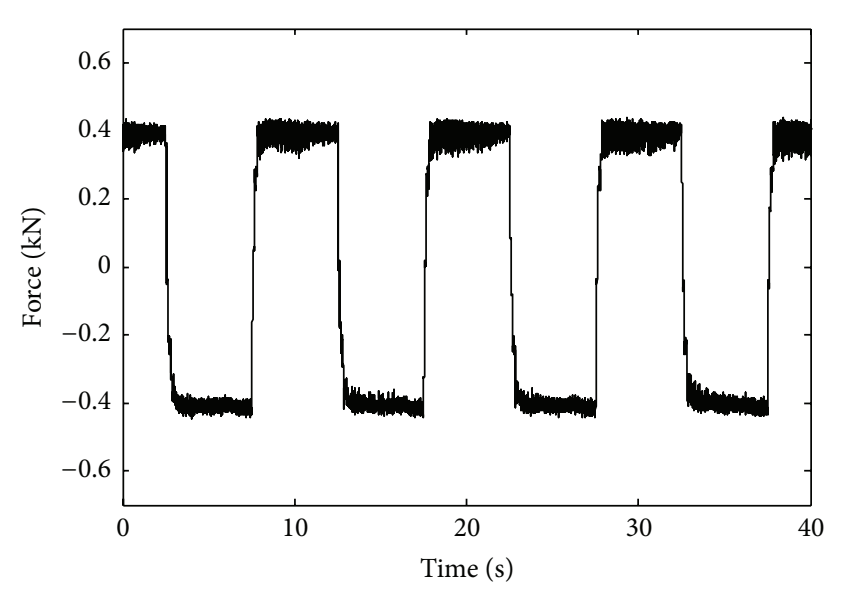

Figure 4: Force in $0.1 \mathrm{~Hz}$.

2.3. Experiment Identification. In this part, experiments are carried out in the INSTRON 8800 bench to test the performance of the fluid inerter. The parameters of the designed fluid inerter are shown in Table 1.

So, the parameters of the nonlinear fluid inerter can be calculated where $b$ is $370 \mathrm{~kg}, C_{1}$ is $790 \mathrm{~N} \cdot \mathrm{s}^{2} \cdot \mathrm{m}^{-2}$, and $C_{2}$ is $4001 \mathrm{~N} \cdot \mathrm{s} \cdot \mathrm{m}^{-1}$.

The structure of the bench test is shown in Figure 3.

The displacement and the force signals can be collected by the sensors in the device. In order to gain the amplitude of friction, the displacement input is set as a triangle wave and the amplitude is $10 \mathrm{~mm}$. Figure 4 shows the force under $0.1 \mathrm{~Hz}$ condition.

It can be noted that the force shapes like a square wave because both the damping force and the inertia force are small enough. It can be inferred that the friction force is a constant value which is $400 \mathrm{~N}$. Furthermore, the fluid inerter is tested under different frequency to verify the theoretical model. The amplitude of the sinusoidal displacement input is set as $20 \mathrm{~mm}$ under the frequency of $0.1 \mathrm{~Hz}, 0.3 \mathrm{~Hz}$, and $0.5 \mathrm{~Hz}, 10 \mathrm{~mm}$ under the frequency of $3 \mathrm{~Hz}, 5 \mathrm{~Hz}$, and $8 \mathrm{~Hz}$, and $5 \mathrm{~mm}$ under the frequency of $10 \mathrm{~Hz}, 12 \mathrm{~Hz}$, and $15 \mathrm{~Hz}$. 


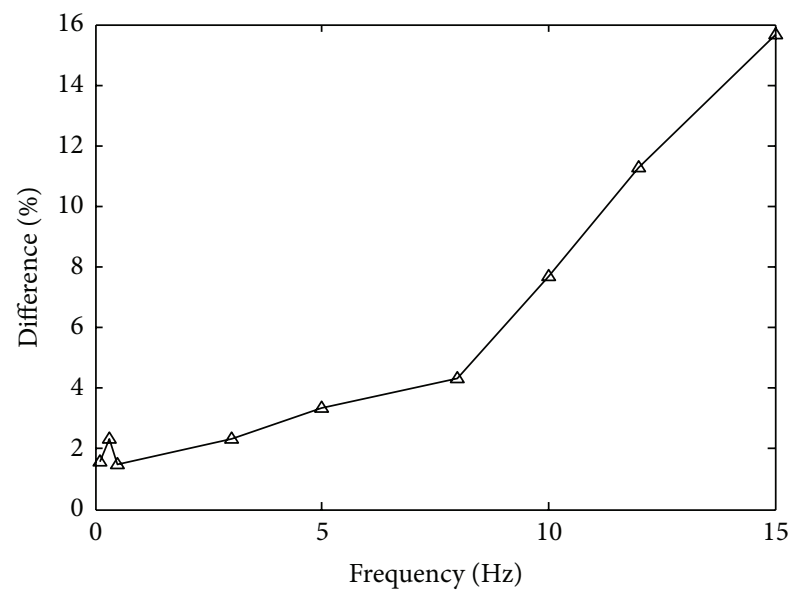

FIgURE 5: Difference between theoretical model and experiment.

TABle 1: Parameters of the fluid inerter.

\begin{tabular}{lc}
\hline Name & Value \\
\hline Radius of piston rod $r_{1} / \mathrm{m}$ & 0.012 \\
Inner radius of the cylinder $r_{2} / \mathrm{m}$ & 0.028 \\
Radius of the helical channel $r_{3} / \mathrm{m}$ & 0.005 \\
Helix radius of channel $r_{4} / \mathrm{m}$ & 0.1 \\
Pitch of helical channel $h / \mathrm{m}$ & 0.012 \\
Circle number of helical channel $n$ & 14 \\
Oil density $\rho / \mathrm{kg} \cdot \mathrm{m}^{-3}$ & 800 \\
Length of transition section $l_{0} / \mathrm{m}$ & 0.1 \\
Viscosity of fluid $\mu / \mathrm{Pa} \cdot \mathrm{s}$ & 0.027 \\
\hline
\end{tabular}

In order to test the effectiveness of the nonlinear model, the mean value of force amplitude under the sinuous displacement input of simulation and experiment is taken into consideration. Figure 5 shows the absolute difference of the force amplitude between theoretical analysis and practical experiment. It can be seen that the second data point is a little larger than the first data point and the third data point, but the absolute differences are all less than $3 \%$, so it can be inferred that the simulation results are very close to the experiment results in low frequency. Furthermore, the absolute difference becomes a little larger with the increase of the frequency. Figure 6 shows the force of the fluid inerter between the theoretical analysis and experiment in $0.5 \mathrm{~Hz}$ and $12 \mathrm{~Hz}$. It can be inferred that the experiment results in higher frequency coincide less well with the simulation than that in low frequency, which may be because the temperature of the fluid has increased for the vibration of the system and the fluid flow is not laminar. In conclusion, the experiment results coincide with the simulation well, which demonstrates the effectiveness of the theoretical model of fluid inerter.

\section{Suspension Involving Nonlinear Inerter}

3.1. Nonlinear Model of Suspension Structure. In [33], a new vehicle suspension employing two springs, one damper and one inerter, was proposed based on the dynamic vibration absorber theory. But the models are all linear which are not exactly in the real condition. In this paper, vehicle suspension employing a nonlinear fluid inerter is investigated. The suspension structure involving the nonlinear fluid inerter is shown in Figure 7.

In Figure 7, $k_{1}$ is the stiffness of main spring, $k_{2}$ is the stiffness of deputy spring, and $c$ is the coefficient of the damper. In this paper, the parameters are optimized by means of the method in [33], where $k_{1}$ is $23.8 \mathrm{kN} / \mathrm{m}, k_{2}$ is $8.9 \mathrm{kN} / \mathrm{m}$, and $c$ is $887 \mathrm{~N} \cdot \mathrm{s} \cdot \mathrm{m}^{-1}$.

3.2. Full-Car Model. A dynamic full-car model is established in Figure 8.

The vehicle body vertical motion equation is

$$
m_{a} \ddot{z}_{a}=F_{10}+F_{20}+F_{30}+F_{40} .
$$

The vehicle body pitching motion equation is

$$
I_{y} \ddot{\varphi}=l_{r}\left(F_{30}+F_{40}\right)-l_{f}\left(F_{10}+F_{20}\right) .
$$

The vehicle body roll motion equation is

$$
I_{x} \ddot{\theta}=\left(F_{20}+F_{40}-F_{10}-F_{30}\right) \frac{d}{2},
$$

where $m_{a}$ is vehicle body mass, $z_{a}$ is the vertical displacement of the vehicle body, $l_{f}$ is the length from the front wheel to the center of vehicle body, $l_{r}$ is the length from the rear wheel to the center of vehicle body, $d$ is the tread between left wheels and right wheels, $I_{x}$ is the body roll moment of inertia, $I_{y}$ is the body pitch moment of inertia, $\theta$ is the roll angle of the vehicle body, $\varphi$ is the pitch angle of the vehicle body, and $F_{i 0}$ is the suspension force.

The motions of four corners of vehicle body are

$$
\begin{aligned}
& Z_{10}=z_{a}-l_{f} \varphi-\frac{d}{2} \theta, \\
& Z_{20}=z_{a}-l_{f} \varphi+\frac{d}{2} \theta, \\
& Z_{30}=z_{a}+l_{r} \varphi-\frac{d}{2} \theta, \\
& Z_{40}=z_{a}+l_{r} \varphi+\frac{d}{2} \theta,
\end{aligned}
$$

where $Z_{i 0}$ is the displacement of the four corners of the vehicle body mass.

For the unsprung mass, the equations are shown as follows:

$$
\begin{aligned}
& m_{1} \ddot{Z}_{1}=k_{t}\left(Q_{1}-Z_{1}\right)-F_{10}, \\
& m_{2} \ddot{Z}_{2}=k_{t}\left(Q_{2}-Z_{2}\right)-F_{20}, \\
& m_{3} \ddot{Z}_{3}=k_{t}\left(Q_{3}-Z_{3}\right)-F_{30}, \\
& m_{4} \ddot{Z}_{4}=k_{t}\left(Q_{4}-Z_{4}\right)-F_{40},
\end{aligned}
$$

where $m_{i}$ is unsprung mass, $k_{t}$ is the tire equivalent stiffness, $Q_{i}$ is the displacements of road, and $Z_{i}$ is vertical displacement of the four unsprung mass. 


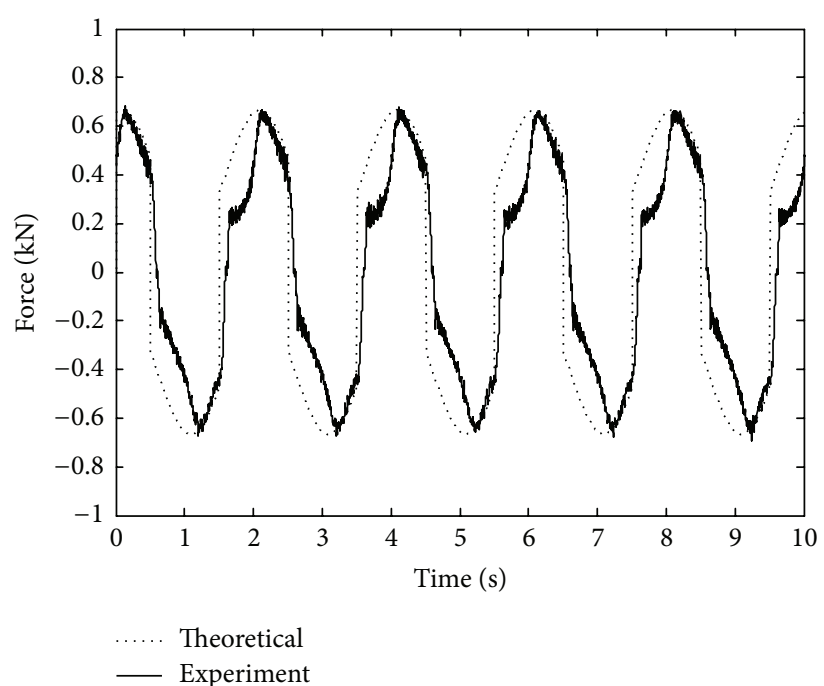

(a) $0.5 \mathrm{~Hz}$

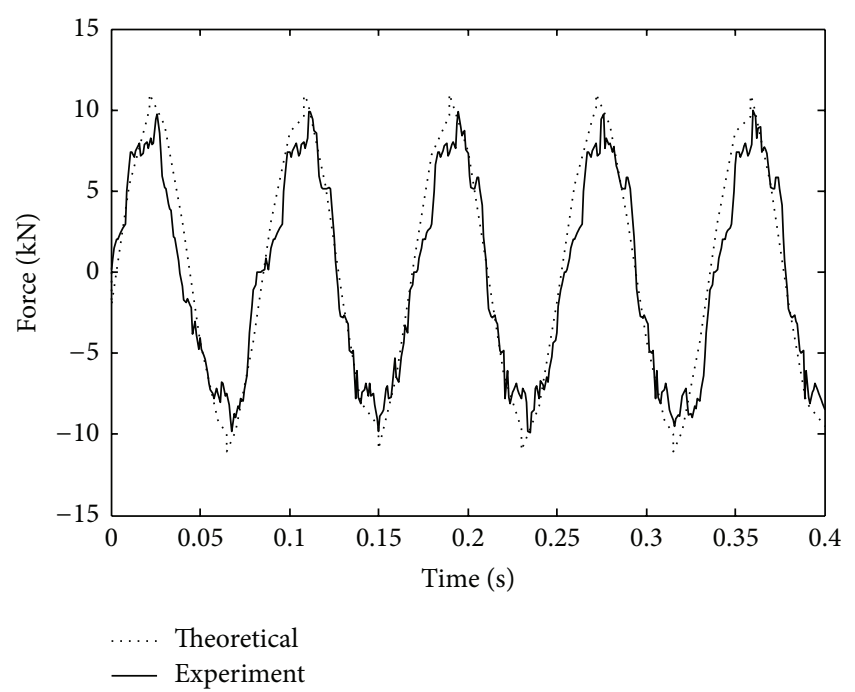

(b) $12 \mathrm{~Hz}$

Figure 6: Force in time domain.

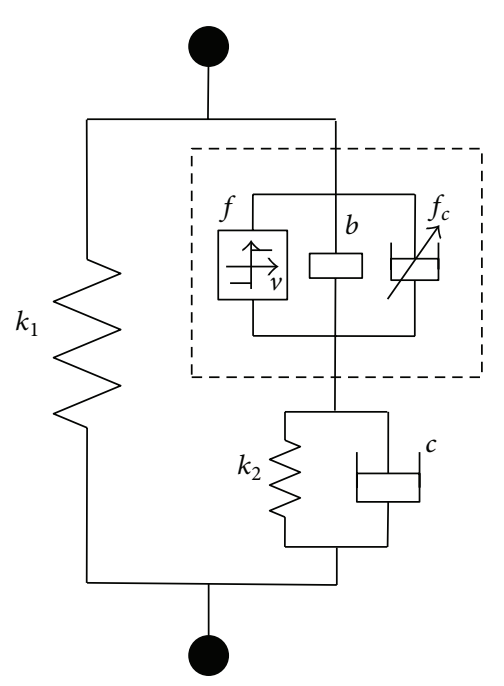

Figure 7: Nonlinear model of suspension structure.

The equations of the suspension force are shown in the following:

$$
\begin{aligned}
& F_{10}= k_{1}\left(Z_{1}-Z_{10}\right)+k_{2}\left(Z_{1}-Z_{b 1}\right)+c\left(\dot{Z}_{1}-\dot{Z}_{b 1}\right) \\
& k_{2}\left(Z_{1}-Z_{b 1}\right)+c\left(\dot{Z}_{1}-\dot{Z}_{b 1}\right) \\
&=f_{0} \operatorname{sign}\left(\dot{Z}_{b 1}-\dot{Z}_{10}\right)+b\left(\ddot{Z}_{b 1}-\ddot{Z}_{10}\right) \\
& \quad+C_{1}\left(\dot{Z}_{b 1}-\dot{Z}_{10}\right)^{2}+C_{2}\left(\dot{Z}_{b 1}-\dot{Z}_{10}\right) \\
& F_{20}= k_{1}\left(Z_{2}-Z_{20}\right)+k_{2}\left(Z_{2}-Z_{b 2}\right)+c\left(\dot{Z}_{2}-\dot{Z}_{b 2}\right)
\end{aligned}
$$

$$
\begin{aligned}
& k_{2}\left(Z_{2}-Z_{b 2}\right)+c\left(\dot{Z}_{2}-\dot{Z}_{b 2}\right) \\
&= f_{0} \operatorname{sign}\left(\dot{Z}_{b 2}-\dot{Z}_{20}\right)+b\left(\ddot{Z}_{b 2}-\ddot{Z}_{20}\right) \\
&+C_{1}\left(\dot{Z}_{b 2}-\dot{Z}_{20}\right)^{2}+C_{2}\left(\dot{Z}_{b 2}-\dot{Z}_{20}\right) \\
& F_{30}= k_{1}\left(Z_{3}-Z_{30}\right)+k_{2}\left(Z_{3}-Z_{b 3}\right)+c\left(\dot{Z}_{1}-\dot{Z}_{b 3}\right) \\
& k_{2}\left(Z_{3}-Z_{b 3}\right)+c\left(\dot{Z}_{3}-\dot{Z}_{b 3}\right) \\
&=f_{0} \operatorname{sign}\left(\dot{Z}_{b 3}-\dot{Z}_{30}\right)+b\left(\ddot{Z}_{b 3}-\ddot{Z}_{30}\right) \\
& \quad+C_{1}\left(\dot{Z}_{b 3}-\dot{Z}_{30}\right)^{2}+C_{2}\left(\dot{Z}_{b 3}-\dot{Z}_{30}\right) \\
& F_{40}=k_{1}\left(Z_{4}-Z_{40}\right)+k_{2}\left(Z_{4}-Z_{b 4}\right)+c\left(\dot{Z}_{4}-\dot{Z}_{b 4}\right) \\
& k_{2}\left(Z_{4}-Z_{b 4}\right)+c\left(\dot{Z}_{4}-\dot{Z}_{b 4}\right) \\
&=f_{0} \operatorname{sign}\left(\dot{Z}_{b 4}-\dot{Z}_{40}\right)+b\left(\ddot{Z}_{b 4}-\ddot{Z}_{40}\right) \\
&+C_{1}\left(\dot{Z}_{b 4}-\dot{Z}_{40}\right)^{2}+C_{2}\left(\dot{Z}_{b 4}-\dot{Z}_{40}\right),
\end{aligned}
$$

where $Z_{b i}$ is the displacement of inerter.

\section{Optimization of the Suspension Parameters}

According to [27], the nonlinearities of inerter may have a bad effect on the vehicle suspension system, so, it seems important to optimize the parameters of the suspension elements. Genetic optimal algorithm originates from the natural selection of biological evolution. It begins from a potential population and then selects the individual according to the fitness. By means of natural genetics operators combining crossover and mutation, new solution stocks will be created. The QGA (quantum genetic algorithm) is the combination 


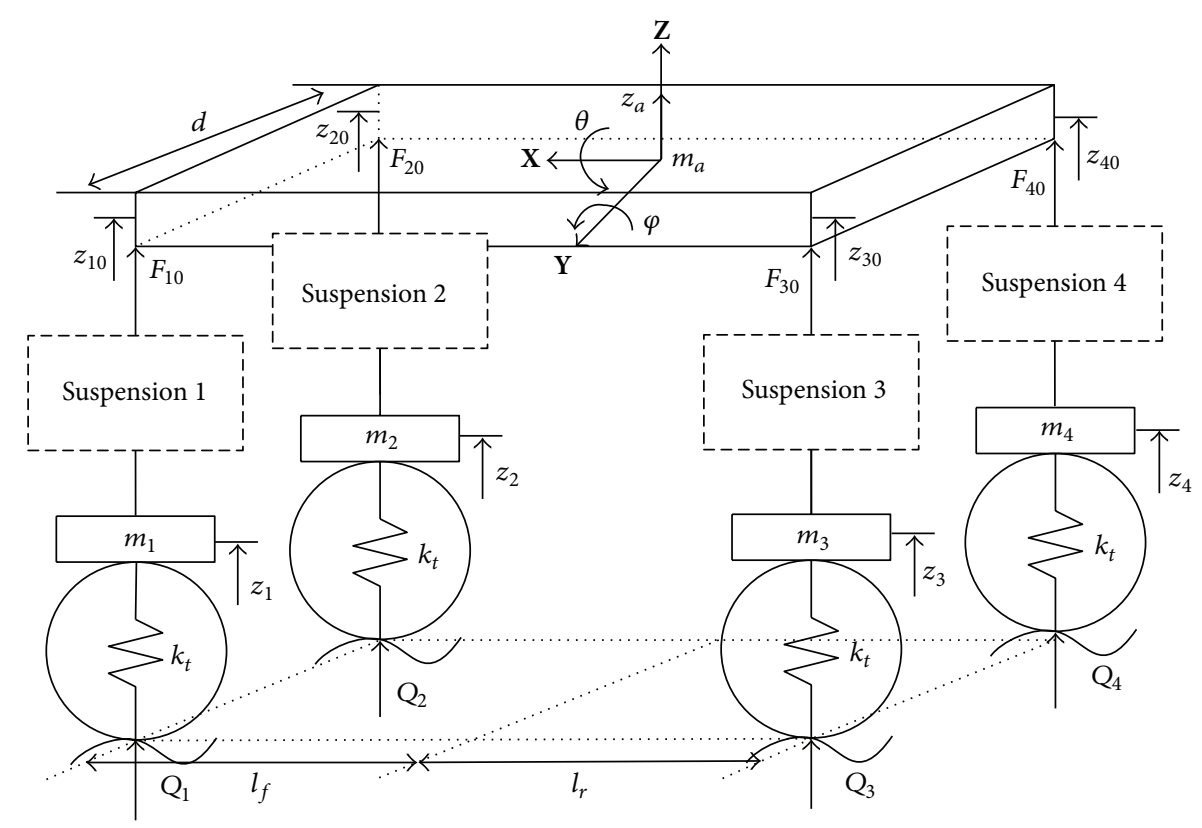

Figure 8: Full-car model.

of genetic algorithm and quantum computing. The quantum state vector is applied to the genetic encoding, and the evolution of chromosome is realized by quantum logic gate.

The updated rules of the quantum bits are

$$
\left[\begin{array}{c}
\alpha_{i}^{\prime} \\
\beta_{i}^{\prime}
\end{array}\right]=U\left(\theta_{i}\right)\left[\begin{array}{l}
\alpha_{i} \\
\beta_{i}
\end{array}\right]
$$

where $\left[\begin{array}{ll}\alpha_{i}^{\prime} & \beta_{i}^{\prime}\end{array}\right]^{T}$ is the updated quantum bit, $\left[\begin{array}{ll}\alpha_{i} & \beta_{i}\end{array}\right]^{T}$ is the original quantum bit, and $U\left(\theta_{i}\right)$ is the updated rotate matrix shown in the following:

$$
U\left(\theta_{i}\right)=\left[\begin{array}{cc}
\cos \left(\theta_{i}\right) & -\sin \left(\theta_{i}\right) \\
\sin \left(\theta_{i}\right) & \cos \left(\theta_{i}\right)
\end{array}\right]
$$

where $\theta_{i}$ is the rotate angle and kept the default values in this paper.

In order to gain the satisfied parameters of suspension, the QGA is used to optimize the parameters of suspension. The population is set as 100; the max number of the population is set as 200. $k_{1}, k_{2}$, and $c$ are chosen as the optimized variables and their ranges are limited as

$$
\begin{aligned}
& 10000 \mathrm{~N} \cdot \mathrm{m}^{-1} \leq k_{1} \leq 30000 \mathrm{~N} \cdot \mathrm{m}^{-1}, \\
& 10000 \mathrm{~N} \cdot \mathrm{m}^{-1} \leq k_{2} \leq 30000 \mathrm{~N} \cdot \mathrm{m}^{-1}, \\
& 100 \mathrm{~N} \cdot \mathrm{s} \cdot \mathrm{m}^{-1} \leq c \leq 3000 \mathrm{~N} \cdot \mathrm{s} \cdot \mathrm{m}^{-1} .
\end{aligned}
$$

The fitness is set as

$$
\min J=w_{1} \frac{A}{A_{0}}+w_{2} \frac{B}{B_{0}}+w_{3} \frac{C}{C_{0}},
$$

where $J$ is the fitness function of the genetic algorithm, $w_{1}, w_{2}$, and $w_{3}$ are the weighting coefficients and set as
0.33, $A$ is the RMS (root-mean-square) of the vertical body acceleration, $B$ is the RMS of the pitch angular acceleration, $C$ is the RMS of the roll angular acceleration of the optimized suspension, $A_{0}$ is the RMS of vertical body acceleration, $B_{0}$ is the RMS of pitch angular acceleration, and $C_{0}$ is the RMS of roll angular acceleration of the original suspension.

There are limitations of the suspension deflection and the dynamic tire load. For suspension deflection, there is $3 \sigma_{f d} \leq$ $\left[f_{d}\right]$, where $\sigma_{f d}$ is the standard deviation of suspension deflection and $\left[f_{d}\right]$ is the limitation of the tire beat distance and set as $8 \mathrm{~cm}$. For dynamic tire load, there is $3 \sigma_{F d} \leq G$, where $\sigma_{F d}$ is the RMS of the dynamic tire load and $G$ is the vehicle static load and set as $2500 \mathrm{~N}$.

The model parameters are listed in Table 2 .

The optimal parameters of suspension are listed in Table 3.

\section{Performance Analysis}

The random road model can be shown in equation

$$
\dot{Q}_{i}(t)=-2 \pi f_{\text {cut }} Q_{i}(t)+2 \pi \sqrt{G_{0} V} w(t),
$$

where $Q_{i}(t)$ is the displacement, $G_{0}$ is the roughness coefficient, $f_{\text {cut }}$ is cut-off frequency, and $V$ is the speed. In this study, $G_{0}$ is $5 \times 10^{-6} \mathrm{~m}^{3}$ cycle ${ }^{-1}$ and $f_{\text {cut }}$ is $0.01 \mathrm{~Hz}$.

In order to show the influences of the nonlinearities of the fluid inerter on the vehicle suspension system, when the speed is set as $20 \mathrm{~m} / \mathrm{s}$, Table 4 shows the performance indexes among the linear suspension, the nonlinear suspension, and the optimized suspension. The linear suspension is the suspension with a linear inerter, the nonlinear suspension is the suspension with a nonlinear fluid inerter, and the optimized suspension is the suspension with a nonlinear inerter whose parameters have been optimized. 
TABLE 2: Model parameters.

\begin{tabular}{lc}
\hline Parameter name & Value \\
\hline Vehicle body mass $m_{a} / \mathrm{kg}$ & 770 \\
Unsprung mass (front) $m_{1}, m_{2} / \mathrm{kg}$ & 37 \\
Unsprung mass (rear) $m_{3}, m_{4} / \mathrm{kg}$ & 33 \\
Tread $d / \mathrm{m}$ & 1.36 \\
Length from front axle to centroid $l_{f} / \mathrm{m}$ & 0.955 \\
Length from rear axle to centroid $l_{r} / \mathrm{m}$ & 1.380 \\
Roll moment inertia $I_{x} / \mathrm{kg} \cdot \mathrm{m}^{2}$ & 293 \\
Pitch moment inertia $I_{y} / \mathrm{kg} \cdot \mathrm{m}^{2}$ & 1074 \\
Stiffness of tire $k_{t} / \mathrm{kN} \cdot \mathrm{m}^{-1}$ & 192 \\
\hline
\end{tabular}

TABLE 3: Optimal parameters.

\begin{tabular}{lc}
\hline Parameters & Value \\
\hline Main spring stiffness $k_{1} / \mathrm{kN} \cdot \mathrm{m}^{-1}$ & 20.1 \\
Deputy spring stiffness $k_{2} / \mathrm{kN} \cdot \mathrm{m}^{-1}$ & 10.2 \\
Damper coefficient $c / \mathrm{N} \cdot \mathrm{s} \cdot \mathrm{m}^{-1}$ & 607
\end{tabular}

It is noted that the suspension performances are all degraded by the nonlinearities of the fluid inerter, the vertical body acceleration increases by $8.3 \%$, the pitch angular acceleration increases by $13.4 \%$, and the roll angular acceleration increases by $1.3 \%$. In [27], the nonlinear ball-screw inerter involving friction and elastic effect was discussed. Results showed that the performance benefits were slightly degraded by ball-screw inerter nonlinearities, which is the same as the fluid inerter. So, we can conclude that the nonlinearities of the inerter will have a slight effect on the suspension performance.

Furthermore, the performance indexes of the optimized suspension are all decreased compared with the nonlinear suspension. The RMS of pitch angular acceleration has dramatically decreased by $19.9 \%$. The RMS of vertical body acceleration has decreased by $9.0 \%$ and the RMS of roll angular acceleration decreased by $9.6 \%$. Figures $9-11$ show the performance indexes in the time domain.

It can be inferred that the vertical body acceleration, the pitch angular acceleration, and the roll angular acceleration are all decreased, which means the vibration isolation performance of optimized suspension is significantly superior to the nonlinear one.

\section{Conclusion}

In this paper, a new fluid inerter is designed and the nonlinearities factors including friction and damping force are analyzed. Experiments have been finished in the bench to test the fluid inerter and to verify the effectiveness of the nonlinear model of fluid inerter. Furthermore, a new vehicle suspension system employing the nonlinear fluid inerter is built and the parameters are obtained by means of quantum genetic algorithm. Results show that the dynamic performance indexes of the optimized suspension all decreased compared with the nonlinear suspension. There is a dramatic decrease which is at most $19.9 \%$ in the RMS

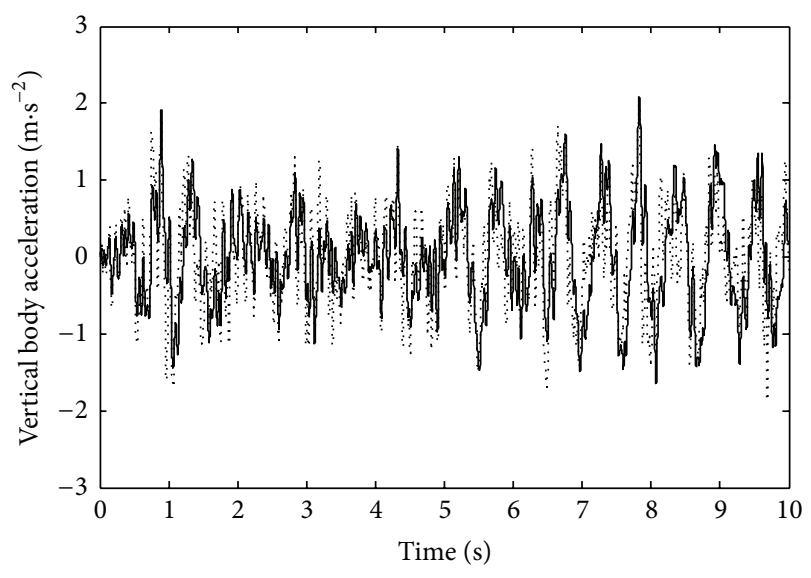

..... Nonlinear

- Optimized

FIGURE 9: Vertical body acceleration.

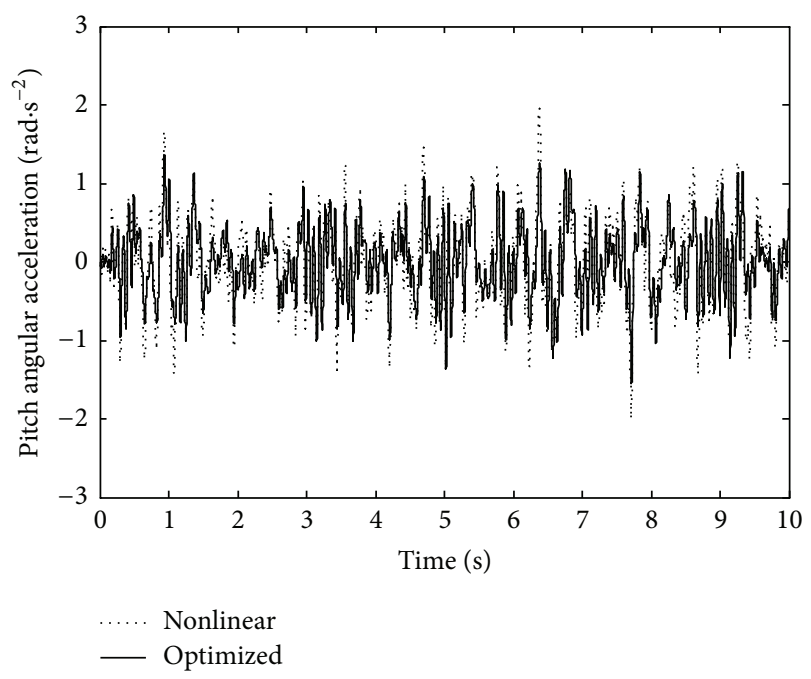

FIGURE 10: Pitch angular acceleration.

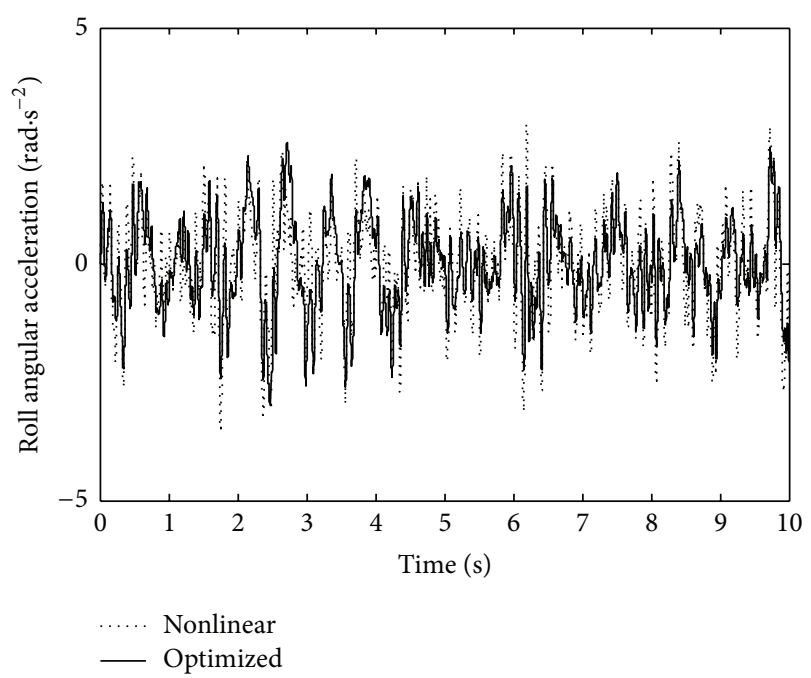

FIGURE 11: Roll angular acceleration. 
TABle 4: Performance indexes.

\begin{tabular}{lcccc}
\hline Name & Linear & Nonlinear & Optimized & Improvement \\
\hline Vertical body acceleration $/\left(\mathrm{m} \cdot \mathrm{s}^{-2}\right)$ & 0.5230 & 0.5668 & 0.5156 & $9.0 \%$ \\
Pitch angular acceleration $/\left(\mathrm{rad} \cdot \mathrm{s}^{-2}\right)$ & 0.4201 & 0.4764 & 0.3815 & $19.9 \%$ \\
Roll angular acceleration $/\left(\mathrm{rad} \cdot \mathrm{s}^{-2}\right)$ & 0.9359 & 0.9478 & 0.8566 & $9.6 \%$ \\
\hline
\end{tabular}

of pitch angular acceleration; the decrease of the RMS of vertical body acceleration is $9.0 \%$ and the decrease of the RMS of roll angular acceleration is $9.6 \%$. The vibration isolation performance is significantly improved.

\section{Competing Interests}

The authors declare that there is no conflict of interests regarding the publication of this paper.

\section{Acknowledgments}

This work was supported by the National Natural Science Foundation of China (Grant no. 51405202), the Scientific Research Innovation Projects of Jiangsu Province (Grant no. KYLX15_1081), the China Postdoctoral Science Foundation (Grant no. 2015M570408), and the "Six Talent Peaks" HighLevel project of Jiangsu Province (Grant no. 2013-JNHB-001).

\section{References}

[1] H. Du and N. Zhang, "Fuzzy control for nonlinear uncertain electrohydraulic active suspensions with input constraint," IEEE Transactions on Fuzzy Systems, vol. 17, no. 2, pp. 343-356, 2009.

[2] H. H. Pan, W. C. Sun, H. J. Gao, and J. Y. Yu, "Finite-time stabilization for vehicle active suspension systems with hard constraints," IEEE Transactions on Intelligent Transportation Systems, vol. 16, no. 5, pp. 2663-2672, 2015.

[3] I. Youn and A. Hac, "Preview control of active suspension with integral action," International Journal of Automotive Technology, vol. 7, no. 5, pp. 547-554, 2006.

[4] M. A. Eltantawie, "Decentralized neuro-fuzzy control for half car with semi-active suspension system," International Journal of Automotive Technology, vol. 13, no. 3, pp. 423-431, 2012.

[5] J. C. Tudon-Martinez, S. Fergani, S. Varrier et al., "Road adaptive semi-active suspension in an automotive vehicle using an LPV controller," in Proceedings of the 7th IFAC Symposium on Advances in Automotive Control (AAC '13), vol. 7, pp. 231-236, Tokyo, Japan, September 2013.

[6] H. Chen, C. Long, C.-C. Yuan, and H.-B. Jiang, "Non-linear modelling and control of semi-active suspensions with variable damping," Vehicle System Dynamics, vol. 51, no. 10, pp. 15681587, 2013.

[7] M. F. Aly, A. O. Nassef, and K. Hamza, "Multi-objective design of vehicle suspension systems via a local diffusion genetic algorithm for disjoint Pareto frontiers," Engineering Optimization, vol. 47, no. 5, pp. 706-717, 2015.

[8] L. R. C. Drehmer, W. J. P. Casas, and H. M. Gomes, "Parameters optimisation of a vehicle suspension system using a particle swarm optimisation algorithm," Vehicle System Dynamics, vol. 53, no. 4, pp. 449-474, 2015.
[9] M. C. Smith, "Synthesis of mechanical networks: the inerter," IEEE Transactions on Automatic Control, vol. 47, no. 10, pp. 1648-1662, 2002.

[10] M. C. Smith, "Force-controlling mechanical device," Patent Pending, International Application no. PCT/GB02/03056, 2001.

[11] M. Z. Q. Chen, C. Papageorgiou, F. Scheibe, F.-C. Wang, and M. Smith, “The missing mechanical circuit element," IEEE Circuits and Systems Magazine, vol. 9, no. 1, pp. 10-26, 2009.

[12] M. Z. Chen, K. Wang, Y. Zou, and G. Chen, "Realization of three-port spring networks with inerter for effective mechanical control," IEEE Transactions on Automatic Control, vol. 60, no. 10, pp. 2722-2727, 2015.

[13] K. Wang and M. Z. Q. Chen, "Minimal realizations of three-port resistive networks," IEEE Transactions on Circuits and Systems I: Regular Papers, vol. 62, no. 4, pp. 986-994, 2015.

[14] M. Z. Q. Chen, K. Wang, M. H. Yin, C. Y. Li, Z. Q. Zuo, and G. R. Chen, "Synthesis of $n$-port resistive networks containing $2 n$ terminals," International Journal of Circuit Theory and Applications, vol. 43, no. 4, pp. 427-437, 2015.

[15] X.-J. Zhang, M. Ahmadian, and K.-H. Guo, "On the benefits of semi-active suspensions with inerters," Shock and Vibration, vol. 19, no. 3, pp. 257-272, 2012.

[16] Y. L. Hu, M. Z. Q. Chen, and Z. Shu, "Passive vehicle suspensions employing inerters with multiple performance requirements," Journal of Sound and Vibration, vol. 333, no. 8, pp. 2212-2225, 2014.

[17] P. Li, J. Lam, and K. C. Cheung, "Control of vehicle suspension using an adaptive inerter," Proceedings of the Institution of Mechanical Engineers, Part D: Journal of Automobile Engineering, vol. 229, no. 14, pp. 1934-1943, 2015.

[18] M. Z. Q. Chen, Y. L. Hu, C. Y. Li, and G. R. Chen, "Performance benefits of using inerter in semiactive suspensions," IEEE Transactions on Control Systems Technology, vol. 23, no. 4, pp. 1571-1577, 2015.

[19] F.-C. Wang, M.-K. Liao, B.-H. Liao, W.-J. Su, and H.-A. Chan, "The performance improvements of train suspension systems with mechanical networks employing inerters," Vehicle System Dynamics, vol. 47, no. 7, pp. 805-830, 2009.

[20] F.-C. Wang and M.-K. Liao, "The lateral stability of train suspension systems employing inerters," Vehicle System Dynamics, vol. 48, no. 5, pp. 619-643, 2010.

[21] F. C. Wang, M. F. Hong, and C. W. Chen, "Building suspension with inerters," Proceedings of the Institution of Mechanical Engineers, Part C: Journal of Mechanical Engineering Science, vol. 224, no. 8, pp. 1605-1616, 2010.

[22] H. L. Sun, P. Q. Zhang, H. B. Chen, K. Zhang, and X. L. Gong, "Application of dynamic vibration absorbers in structural vibration control under multi-frequency harmonic excitations," Applied Acoustics, vol. 69, no. 12, pp. 1361-1367, 2008.

[23] L. Marian and A. Giaralis, "Optimal design of a novel tuned mass-damper-inerter (TMDI) passive vibration control configuration for stochastically support-excited structural systems," Probabilistic Engineering Mechanics, vol. 38, pp. 156-164, 2014. 
[24] Y. L. Hu and M. Z. Q. Chen, "Performance evaluation for inerter-based dynamic vibration absorbers," International Journal of Mechanical Sciences, vol. 99, pp. 297-307, 2015.

[25] M. Z. Q. Chen, Y. Hu, L. Huang, and G. Chen, "Influence of inerter on natural frequencies of vibration systems," Journal of Sound and Vibration, vol. 333, no. 7, pp. 1874-1887, 2014.

[26] Y. L. Hu, M. Z. Q. Chen, Z. Shu, and L. X. Huang, "Analysis and optimisation for inerter-based isolators via fixed-point theory and algebraic solution," Journal of Sound and Vibration, vol. 346, no. 1, pp. 17-36, 2015.

[27] F.-C. Wang and W.-J. Su, "Impact of inerter nonlinearities on vehicle suspension control," Vehicle System Dynamics, vol. 46, no. 7, pp. 575-595, 2008.

[28] S. J. Swift, M. C. Smith, A. R. Glover, C. Papageorgiou, B. Gartner, and N. E. Houghton, "Design and modelling of a fluid inerter," International Journal of Control, vol. 86, no. 11, pp. 2035-2051, 2013.

[29] A. R. Glover, M. C. Smith, and N. E. Houghton, "Forcecontrolling hydraulic device," International Patent Application No: PCT/GB2010/001491, 2009.

[30] C. Papageorgiou and M. C. Smith, "Laboratory experimental testing of inerters," in Proceedings of the 44th IEEE Conference on Decision and Control, and the European Control Conference, pp. 3351-3356, Seville, Spain, December 2005.

[31] F.-C. Wang, M.-F. Hong, and T.-C. Lin, "Designing and testing a hydraulic inerter," Proceedings of the Institution of Mechanical Engineers, Part C: Journal of Mechanical Engineering Science, vol. 225, no. 1, pp. 66-72, 2011.

[32] B. S. Massey, Mechanics of Fluids, Chapman \& Hall, London, UK, 6th edition, 1997.

[33] Y. Shen, L. Chen, X. Yang, D. Shi, and J. Yang, "Improved design of dynamic vibration absorber by using the inerter and its application in vehicle suspension," Journal of Sound and Vibration, vol. 361, pp. 148-158, 2016. 


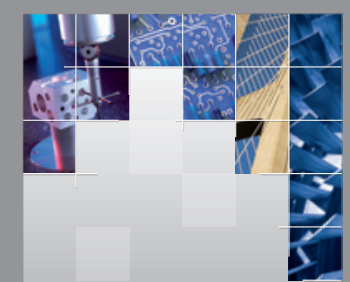

\section{Enfincering}
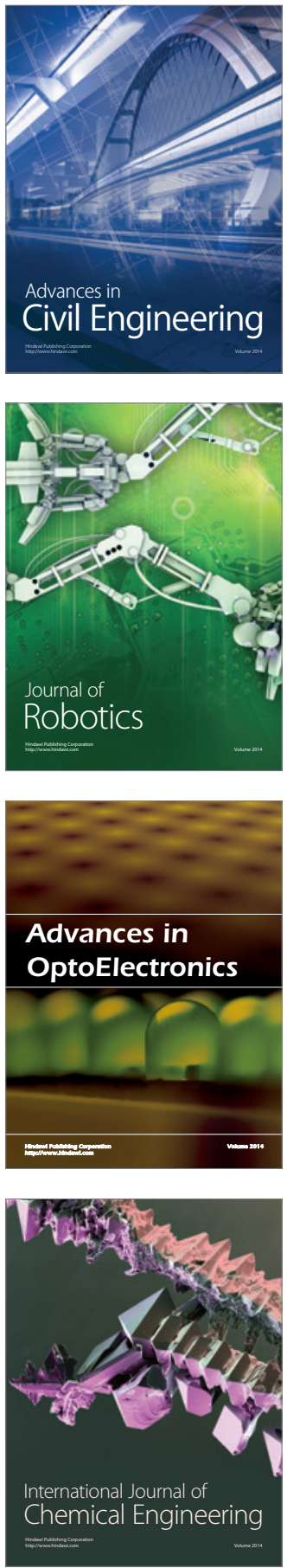

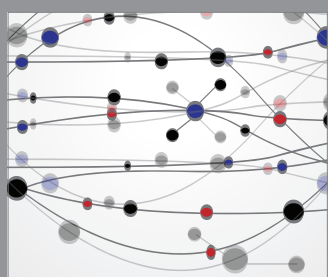

The Scientific World Journal

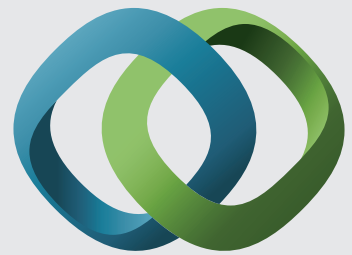

\section{Hindawi}

Submit your manuscripts at

http://www.hindawi.com
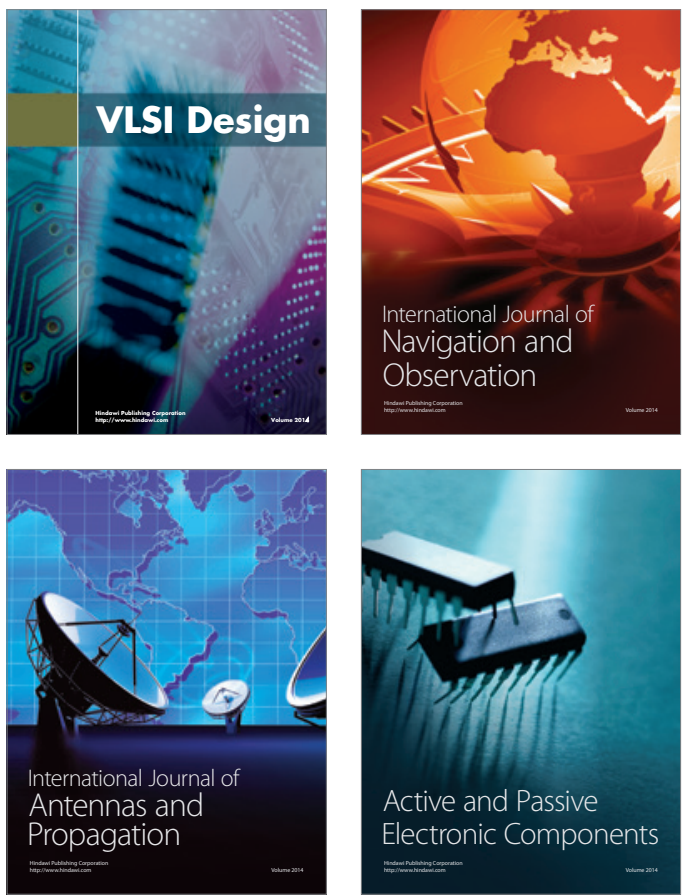
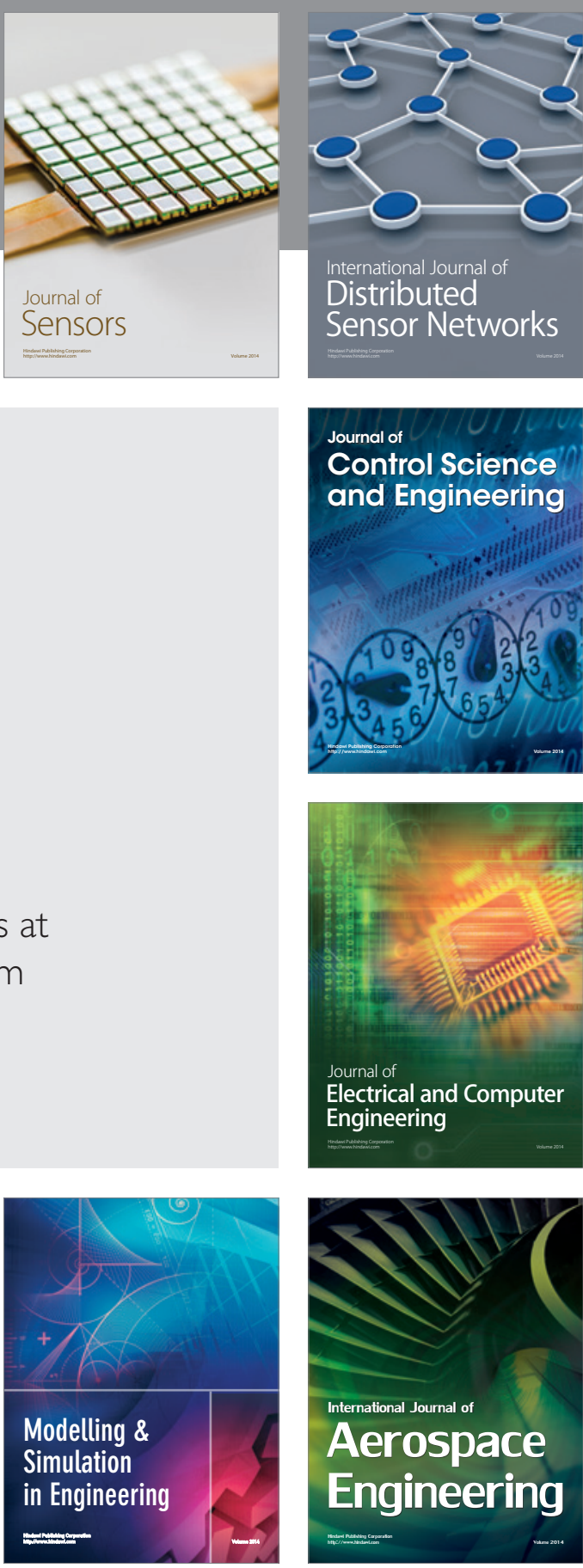

International Journal of

Distributed

Sensor Networks

Journal of

Control Science

and Engineering
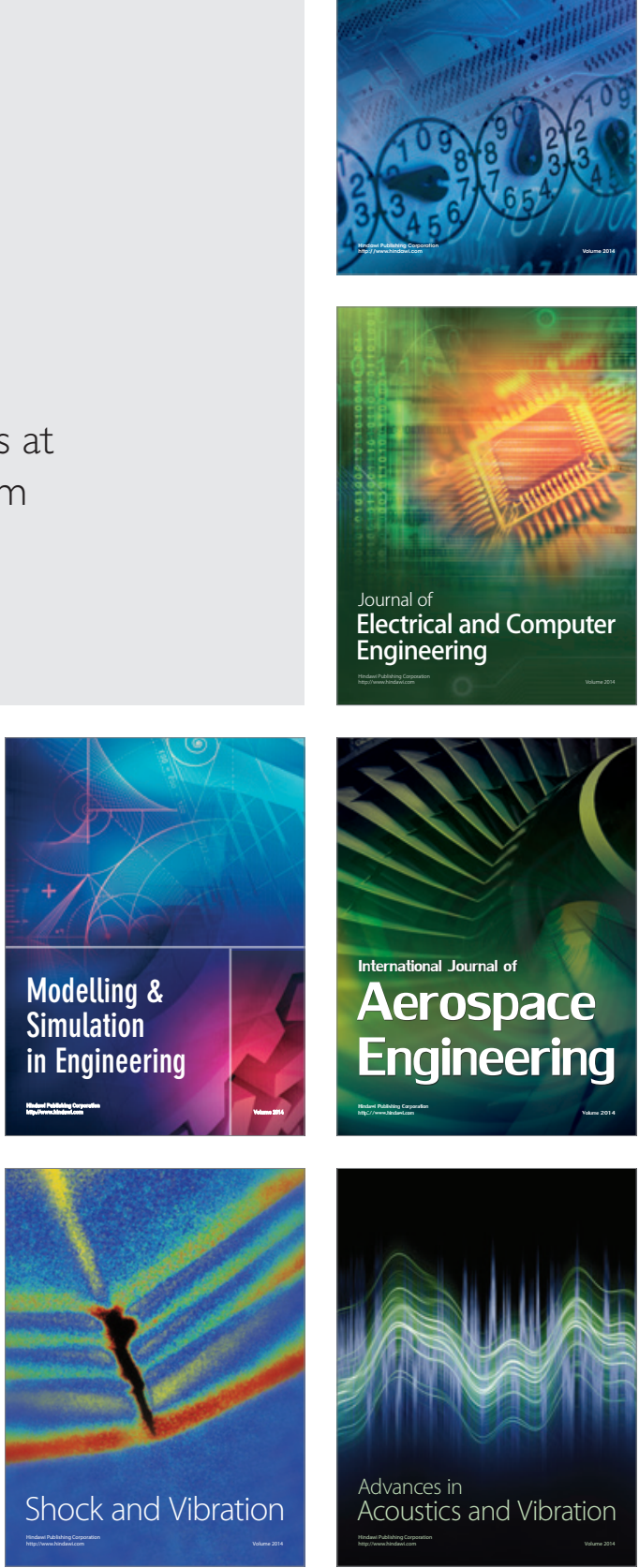